\title{
RANCANG BANGUN SISTEM INFORMASI PEMBAYARAN SEKOLAH BERBASIS WEB DI SDIT CORDOVA 1 KOTA TANGERANG
}

\author{
Abdul hayat ${ }^{1}$ \\ Mardiana $^{2}$ \\ Fajar Firdaus ${ }^{3}$ \\ Program Studi Komputerisasi Akuntansi, AMIK Raharja Informatika ${ }^{1,2,3}$

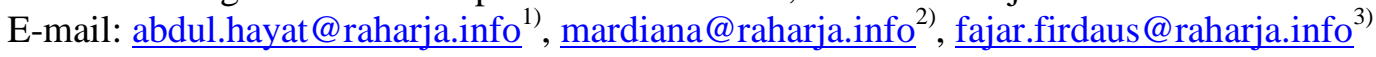

\begin{abstract}
ABSTRAK
Perkembangan Teknologi Informasi telah merambah ke berbagai aspek kehidupan, termasuk adalah di bidang pendidikan khususnya pada penerapan aplikasi Teknologi Informasi di tingkat SD. Jurnal ini mengupas tentang perancangan sebuah sistem informasi yang pada umumnya digunakan di sekolah, yakni Sistem Informasi Pembayaran Sekolah pada SDIT CORDOVA 1 Kota Tangerang. Penggunaan sistem informasi pembayaran yang berjalan pada sekolah tersebut selama ini belum terintegrasi, sebagian proses pencatatan transaksi dilakukan dengan sederhana dengan bantuan aplikasi spreadsheet; dan sebagian proses pencatatan lainnya masih dilakukan dengan cara mencatatnya dalam sebuah buku, dengan kata lain dilakukan dengan cara manual. Hal ini dalam praktik kesehariannya didapati beberapa masalah, antara lain lamanya proses untuk mendapatkan informasi tentang status pembayaran uang SPP, uang iuran lainnya, beberapa tools tidak bekerja dengan sebagaimana mestinya sesuai dengan apa yang diharapkan oleh user, dan sebagainya. Oleh sebab itu, untuk mendukung sistem pembayaran dibutuhkan sistem yang terintegrasi dengan baik, sehingga segala proses transaksi berjalan dengan akurat. Metode yang dilakukan untuk mengembangkan sebuah sistem informasi ini adalah dengan menerapkan pendekatan System Development Life-Cycle (SDLC). Analisis dan desain sistem dilakukan dengan menggunakan UML, Visual Paradigm, dan program aplikasinya menggunakan bahasa PHP serta database MySQL. Hasil penelitian ini adalah berupa Sistem Informasi Pembayaran Sekolah Berbasis Web.
\end{abstract}

Kata Kunci: Sistem Informasi Pembayaran, Berbasis Web, SDLC

\section{ABSTRACT}

Development of Information Technology has penetrated its use to various aspects of life, including in the field of education, especially in this case the application of Information Technology at the elementary school level. This paper discusses the design of all about payment, so called School Payment Information System at SDIT CORDOVA 1 Kota Tangerang. Management of Payment Information System at the school hasn't been done in an integrated manner, part of the process of transaction done by using spreadsheet application and some other process done manually. There are found some problems in day-to day practice, e.g. the duration process to get information about the status of payment of SPP is relatively time consuming, also for non-SPP, some tools often do not work properly as desired by the user, and so forth. Therefore, to support the payment system requires a well-integrated system, so that all the transaction proceedings run accurately. The method used to develop the Information System is by applying the System Development Life-Cycle (SDLC) approach. System analysis and design using UML, Visual Paradigm software, and application program created using PHP and MySQL database.

Keywords: Information System of Payment, web based, SDLC 


\section{PENDAHULUAN}

Seiring dengan perkembangan teknologi informasi di era globalisasi ini semakin memberikan pengaruh yang sangat bersar terhadap keberlangsungan hidup manusia, karena teknologi informasi menjadi sebuah kebutuhan yang sangat penting dan dicari bahkan tiap individu dituntut harus dapat mengusai teknologi informasi. Perkembangan teknologi informasi dari waktu ke waktu mengalami kemajuan yang sangat pesat bahkan beraneka ragam. Bahkan teknologi informasi mampu menciptakan trend yang selalu diminati. Di masa sekarang ini fungsi dari teknologi informasi digunakan oleh berbagai kalangan, mulai dari individu sampai pada perusahaan serta instansi pemerintah.

Di bidang pendidikan pada saat ini sudah mulai mengenal teknologi informasi, bahkan ikut andil dalam setiap proses perkembangannya. Sistem pendidikan pada saat ini juga mulai mengunakan teknologi informasi pada setiap aktivitas sekolah, termasuk di dalamnya penerapan program aplikasi komputer yang khususnya berhubungan dengan administrasi pembayaran. Dalam hal ini setiap aspek pendidikan memerlukan adanya teknologi informasi dalam menunjang keberlangsungan pendidikan di Indonesia. Sudah seharusnya pendidikan pada saat ini ditunjang dengan adanya teknologi informasi yang canggih untuk memudahkan pada pelajar, agar dapat bersaing pada dunia luar serta dapat berperan dalam proses perkembangan teknologi informasi pada era sekarang atau bahkan di era mendatang.

Dalam hal ini setiap individu, perusahan, maupun instansi yang menggunakan teknologi informasi harus mampu mengembangkan sistem yang mereka gunakan, sehingga tidak lagi tertinggal pada era mendatang, karena teknologi informasi selalu diperbarui setiap saat, bisa setiap tahun, setiap bulan, dan setiap jam, bahkan bisa setiap menit. Oleh karena itu diperlukan sistem yang efektif dan efisien, serta tenaga yang baik dalam mengoperasikan serta mengembangkannya. Dengan adanya trend teknologi informasi ini mendorong penulis untuk mengembangkan sebuah sistem informasi mengenai sistem pembayaran yang ada pada SDIT CORDOVA 1 Kota Tangerang. Karena sistem informasi ini termasuk bagian dari faktor keberhasilan dan juga keberlangsungan SDIT Cordova 1 Kota Tangerang saat ini dan juga masa datang.

\section{LITERATURE REVIEW}

Sebelumnya terdapat banyak penelitian yang dilakukan mengenai sistem pembayaran dalam upaya meningkatkan kualitas pelayanan dan memudahkan proses pengolahan dan pembuatan laporan keuangan. Diantaranya mengidentifikasi kesenjangan, mengidentifikasi metode yang pernah dilakukan serta mengetahui orang lain yang spesialisasi dan era penelitiannya sama dibidang ini. Beberapa literature review tersebut adalah sebagai berikut :

1. Penelitian yang dilakukan oleh Muhyiddin Zainul Arifin, Martin Nuril Huda yang berjudul "Pembuatan Dan Perancangan Sisitem Informasi Pembayaran Sekolah Dengan Microsoft Visual Fox Pro Di SMA Muhammadiyah 1 Jombang". Pembuatan sistem informasi pembayaran sekolah menggunakan program microsoft visual fox pro. Hal ini digunakan untuk membantu dan memudahkan pengguna dalam pengarsipan data, pencarian data, penghapusan data atau pembaharuan data pembayaran siswa pada sistem database dengan cepat, baik, efisien, tertib sehingga akan meningkatkan kinerja sekolah. [1]

2. Penelitian yang dilakukan oleh Muhammad Hasan Wahid yang berjudul "Pemanfaatan Teknologi SMS Gateway Pada Sistem Pembayaran SPP dan Tabungan Sekolah di SMA N 1 Nalumsari", membahas tentang perancangan sistem informasi untuk mempermudah bagian tata usaha dalam mengelola proses transaksi spp dan tabungan Sistem ini dirancang dengan menggunakan pemodelan UML. Sedangkan bahasa pemrograman yang digunakan adalah $\mathrm{Vb}$ Net 2010 dan database MySQL. [2]

3. Penelitian yang dilakukan oleh Mentari Adhani, dkk. berjudul "Analisa dan Perancangan Sistem Informasi Penerimaan Siswa Baru dan Pembayaran SPP Menggunakan Zachman Framework", membahas tentang perancangan sistem informasi yang dapat membantu mempercepat proses penerimaan baru dan mengurangi kesalahan perhitungan dalam proses pembayaran biaya (Payment Order) menggunakan metode Kerangka kerja Zachman. [3] 


\section{METODOLOGI}

Metode penelitian yang digunakan untuk mengembangkan sebuah sistem informasi ini adalah dengan menerapkan pendekatan System Development Life-Cycle (SDLC) yang terdiri dari tahap analisis, desain, rancangan prototype. Analisis dan desain sistem digambarkan menggunakan Diagram Unified Modelling Language (UML), dan rancangan sistem aplikasinya menggunakan bahasa pemrograman PHP serta database MySQL.

\section{HASIL DAN PEMBAHASAN}

\section{a. Analisa Sistem}

Tahap analisa merupakan tahap penelitian atas sistem yang berjalan dengan tujuan mengetahui prosedur sistem yang berjalan. Analisis sistem digambarkan menggunakan Diagram Unified Modelling Language (UML), diantaranya Use Case Diagram sebagai berikut :

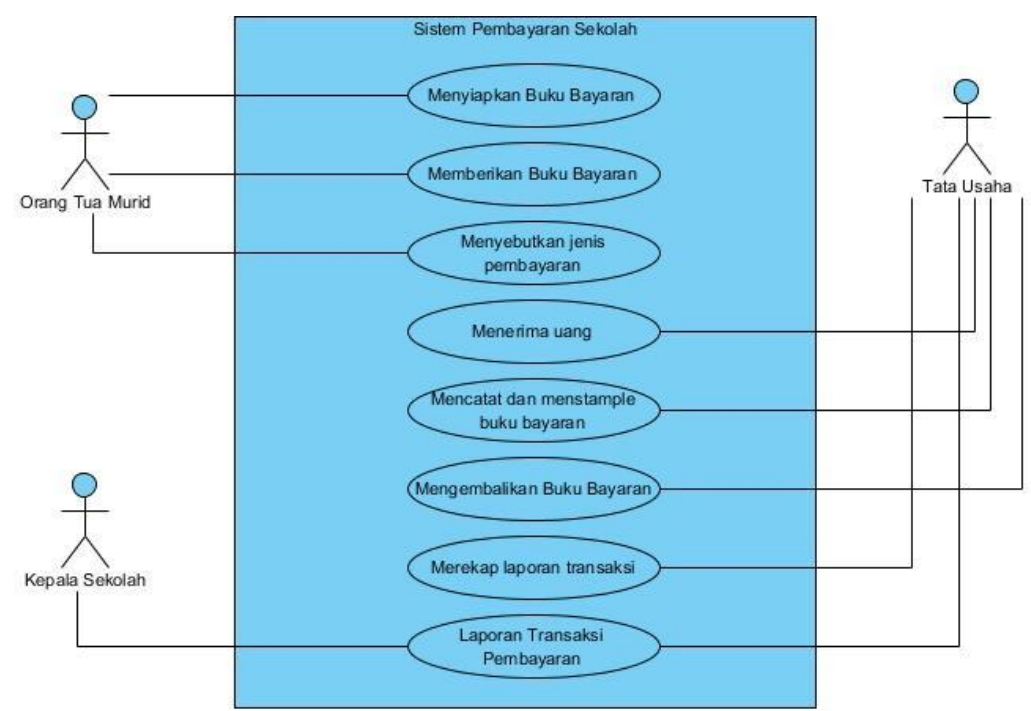

Gambar 1. Use Case Diagram

Berdasarkan gambar 1 use case diagram, maka dijelaskan sebagai berikut:

1. Terdapat 1 (satu) sistem yang mencakup seluruh proses pembayaran di SDIT Cordova 1 Kota Tangerang tersebut.

2. Terdapat 3 (tiga) actor yang melakukan kegiatan dalam proses transaksi pembayaran, yang diantaranya Orang Tua Siswa, Petugas Tata Usaha, dan Kepala Sekolah.

3. Terdapat 8 (delapan) Use Case yang dilakukan oleh masing-masing Actor, diantaranya: Orang Tua Siswa menyiapkan buku bayaran, memberikan buku bayaran, menyebutkan jenis transaksi bayaran yang ingin dilakukan, menerima uang, mencatat dan menstempel buku bayaran, mengembalikan buku bayaran, merekap laporan transaksi yang terjadi, dan membuat laporan transaksi pembayaran.

\section{b. Desain Sistem}

Tahap perancangan merupakan tahapan dalam menentukan proses dan data yang dibutuhkan oleh sistem yang diusulkan dengan tujuan memenuhi kebutuhan user. Alat bantu (tools) yang digunakan adalah software visual paradigm untuk mendeskripsikan Use Case Diagram, Class Diagram dan Activity Diagram. Kemudian berdasarkan use case diagram, activity diagram, sequence diagram, selanjutnya adalah membuat rancangan antar muka (interface) yang akan diterapkan dalam program aplikasi. Dengan demikian proses implementasi atau penulisan program (coding) dapat lebih terarah. 
1. Use Case Diagram Usulan

Use Case Diagram menggambarkan fungsional yang diharapkan dari sebuah sistem yang dibangun. Berikut ini adalah Use Case Diagram yang diusulkan untuk Sistem Pembayaran Sekolah Di Sekolah SDIT Cordova 1 Kota Tangerang.

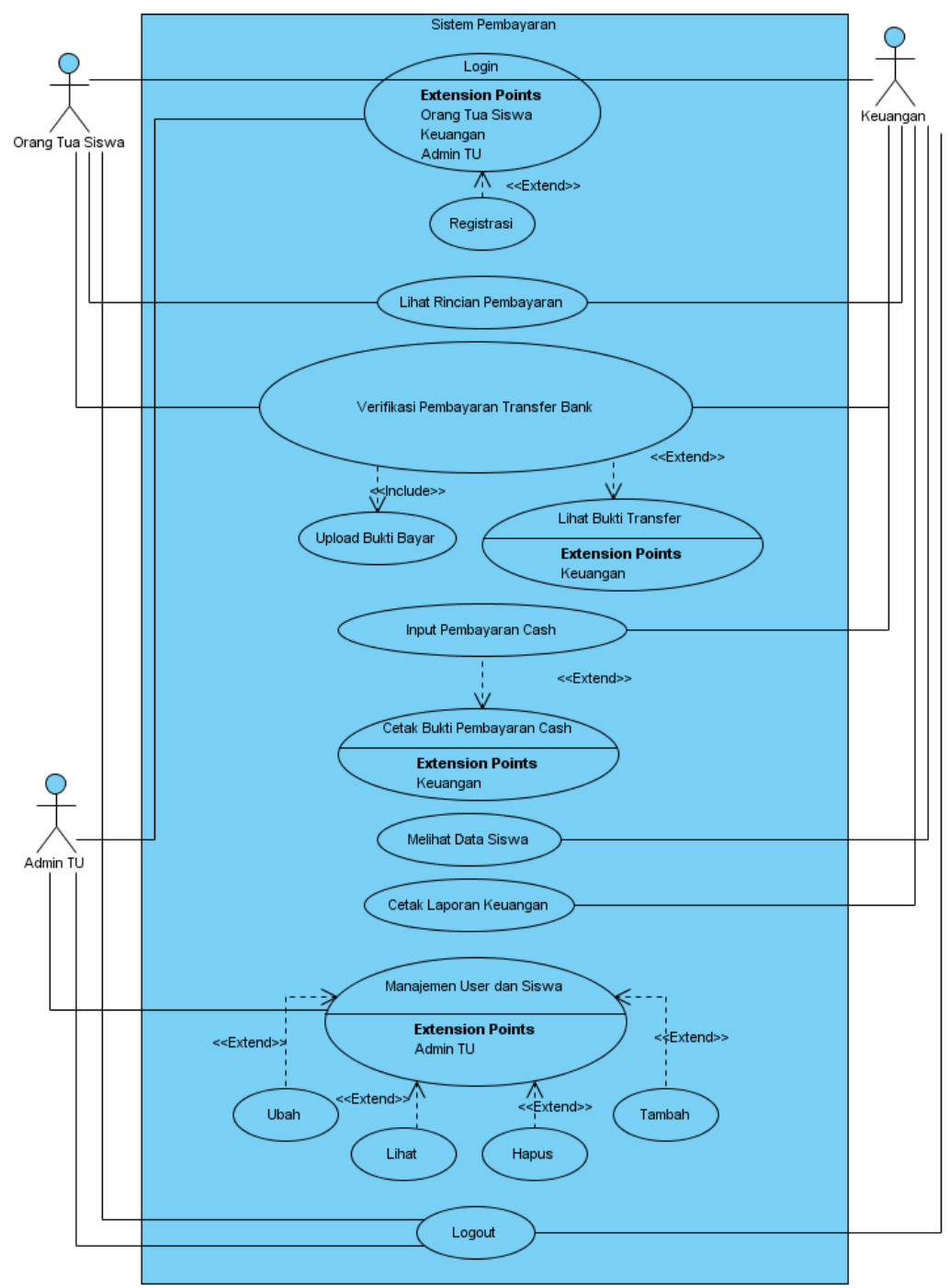

Gambar 2. Use Case Diagram Usulan

Berdasarkan Gambar 3.5 diatas terdapat:

1. 1 Sistem yang mencakup seluruh kegiatan sistem pembayaran sekolah pada SDIT Cordova 1 Kota Tangerang.

2. Terdapat 3 Actor yang melakukan kegiatan, yaitu: Orang Tua, Admin TU, Bagian Keuangan.

3. Terdapat 9 Use Case, yaitu : login, lihat rincian pembayaran, verifikasi pembayaran transfer bank, input pembayaran cash, cetak bukti pembayaran cash, melihat data siswa, cetak laporan keuangan, dan manajemen user dan siswa, serta logout.

4. Terdapat 7 Extend yaitu : registrasi, lihat bukti transfer, cetak bukti pembayaran cash, menu ubah, lihat, hapus dan tambah.

5. Terdapat 1 Include, yaitu upload bukti bayar.

2. Activity Diagram Usulan

Activity Diagram menggambarkan berbagai alur aktifitas dalam sistem yang sedang dirancang, bagaimana masing-masing alur, decision yang terjadi dan bagaimana mereka 
berakhir. Berikut ini adalah Activity Diagram diusulkan untuk Sistem Pembayaran Sekolah di SDIT Cordova 1 Kota Tangerang.

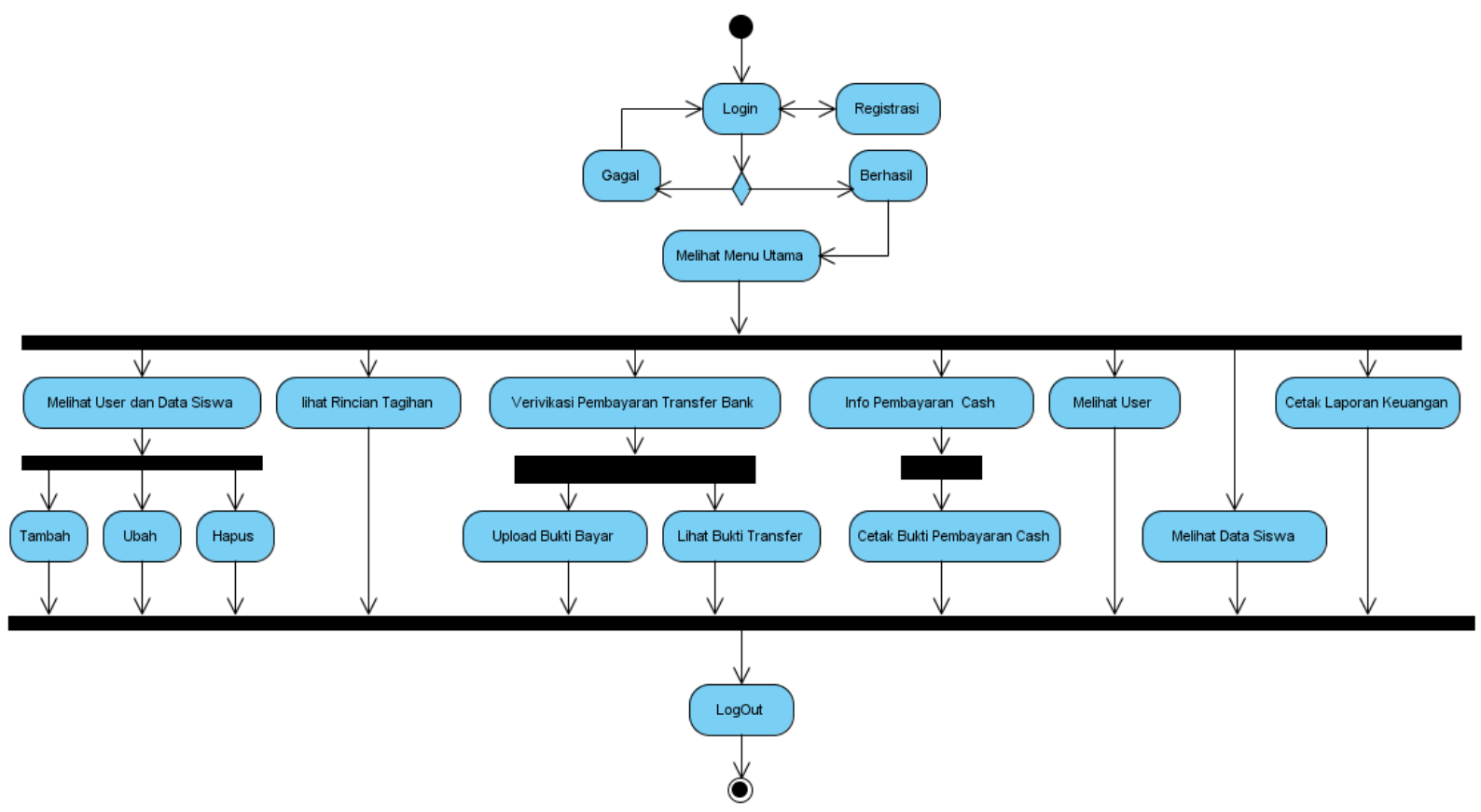

Gambar 3. Activity Diagram Usulan

Berdasarkan gambar 3 diatas terdapat:

1. 1 (satu) initial node, sebagai objek yang diawali.

2. 1 (satu) decision node, yang menggambarkan Test Condition untuk memastikan Flow Control mengalir lebih ke satu jalur.

3. 19 (sembilan belas) action dari sistem yang mencerminkan eksekusi dari suatu aksi.

4. 5 (lima) fork node dari sistem yang mencerminkan penggabungan action.

5. 1 (satu) final node, sebagai objek yang diakhiri.

\section{c. Rancangan Prototype Sistem}

Tahap ini merupakan gambaran mengenai rancang bangun yang lengkap terhadap para pengguna dan website yang dikembangkan, dan juga sebagai pemenuhan kebutuhan dari pada para pengguna sistem. Bahasa pemrogram yang digunakan sama dengan bahasa pemrograman yang digunakan untuk program yang sebenarnya, yakni PHP, dan database MySQL. Desain interface-nya menggunakan bantuan aplikasi Dreamweaver CS3. Berikut adalah prototype sistem pembayaran di SDIT Cordova 1 Kota Tangerang yang dibangun:

1. Tampilan Login User

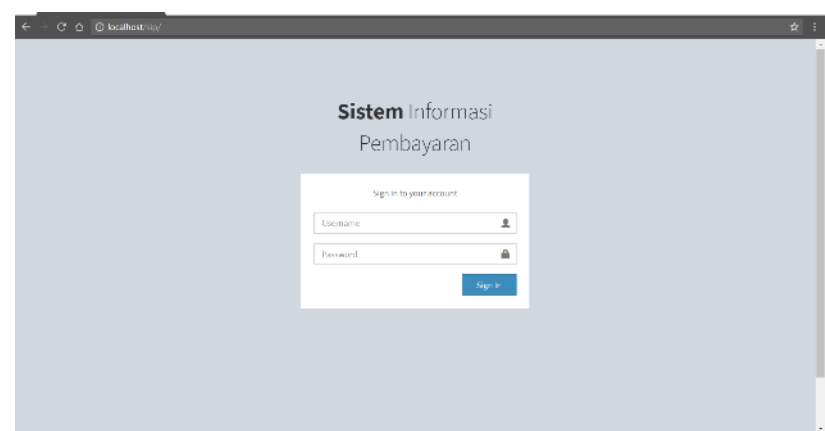

Gambar 4. Tampilan Login User 
Gambar 4 merupakan tampilan login user yang digunakan user agar dapat mengakses dashboard sistem. Ada 3 pengguna yang diberi hak akses ke dalam sistem ini, yaitu admin, bagian keuangan dan orang tua siswa.

2. Tampilan Dashboard Admin

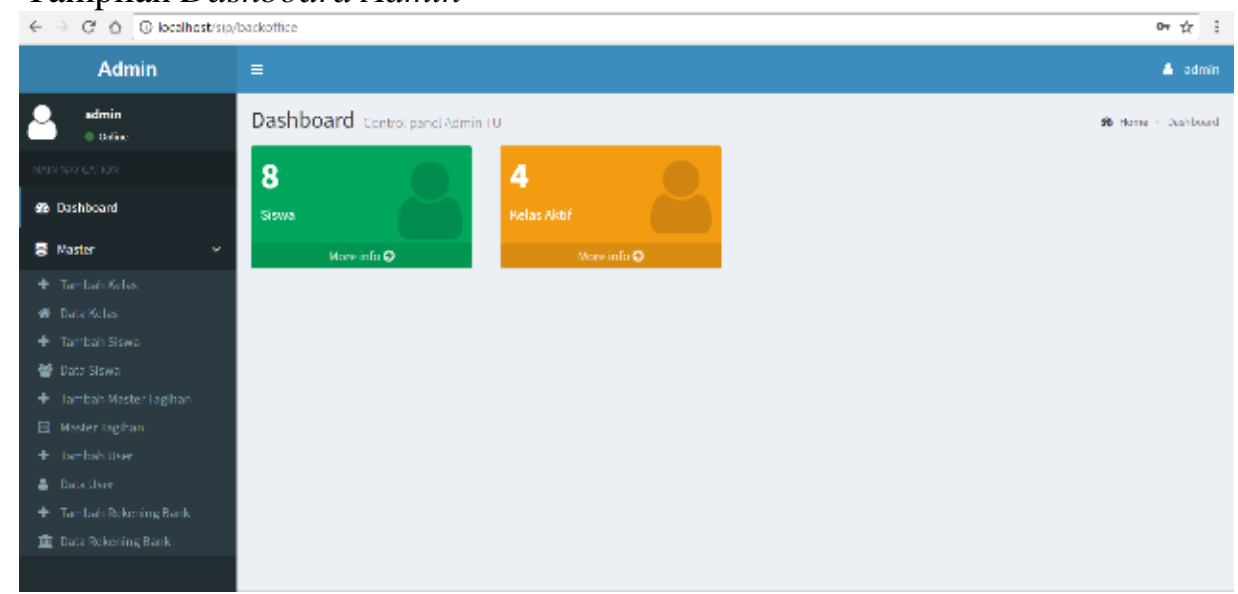

Gambar 5. Halaman Dashboard Admin

Gambar 5 merupakan halaman dashboard yang dapat di akses oleh admin, terdiri dari menu kelas, menu siswa, menu tagihan, menu user, menu rekening bank.

3. Tampilan Dashboard Keuangan

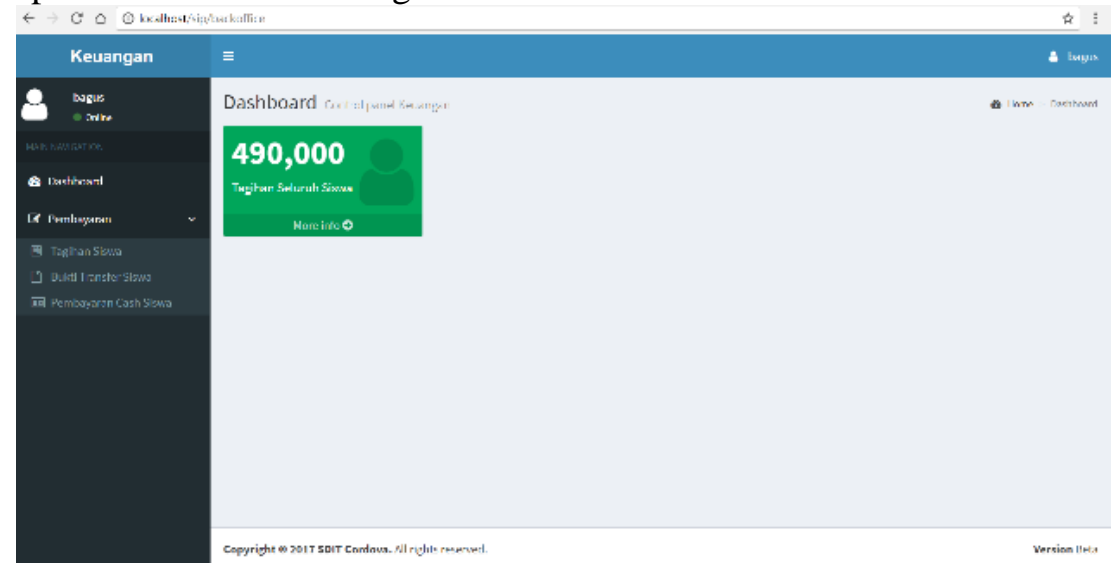

Gambar 6. Dashboard Bagian Keuangan

Gambar 6 merupakan tampilan dashboard untuk login bagian keuangan, digunakan untuk proses pembayaran siswa, diantaranya menu tagihan siswa, bukti transfer siswa dan pembayaran cash siswa. 
4. Halaman Tagihan Siswa

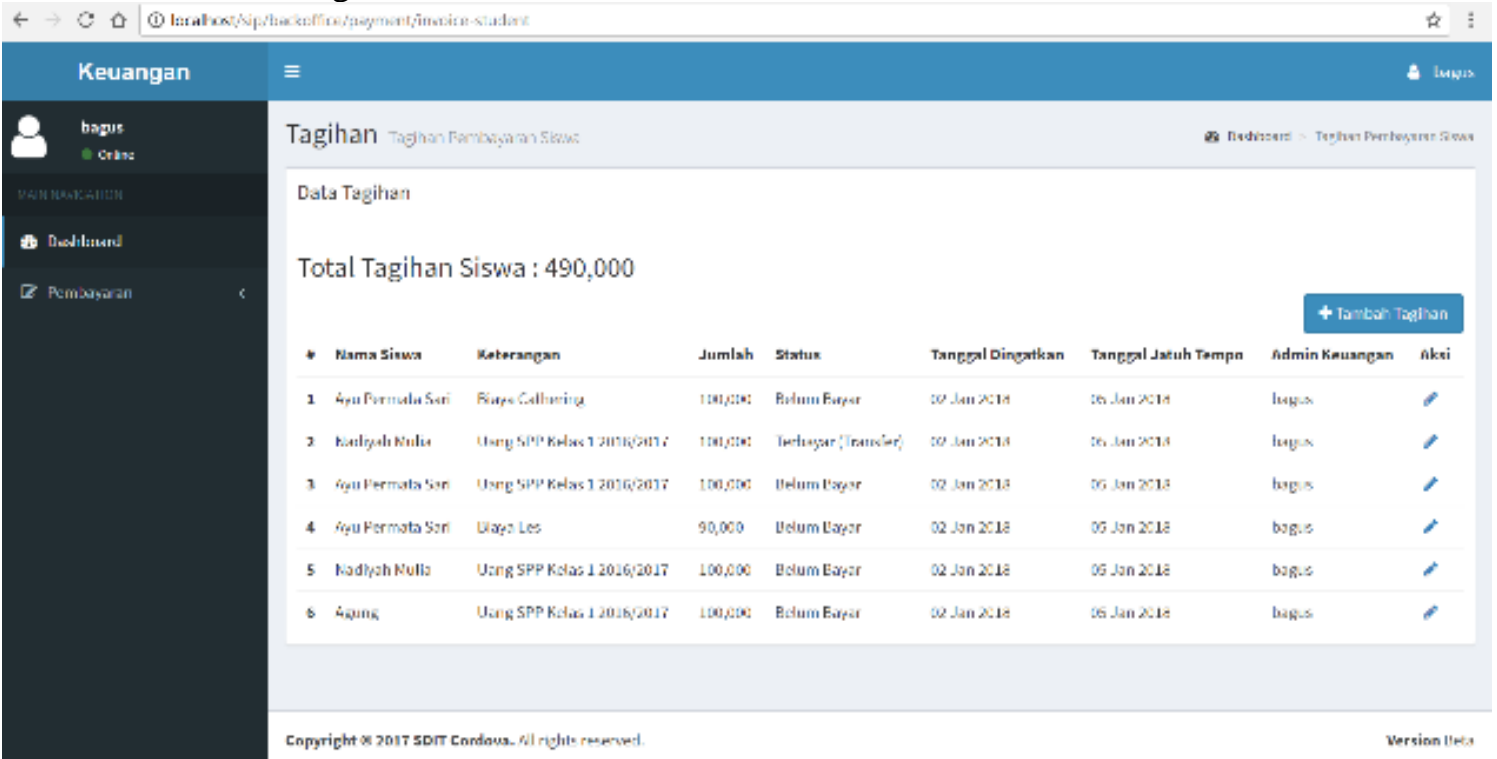

Gambar 7. Halaman Tagihan Siswa

Pada gambar 7, bagian keuangan dapat melihat tagihan siswa secara keseluruhan, terdiri dari nama siswa, keterangan, jumlah tagihan, status, tanggal jatuh tempo, sehingga bagian keuangan lebih mudah mengecek daftar siswa yang masih memiliki tagihan dan memudahkan dalam pembuatan laporan.

5. Tampilan Dashboard Orang Tua

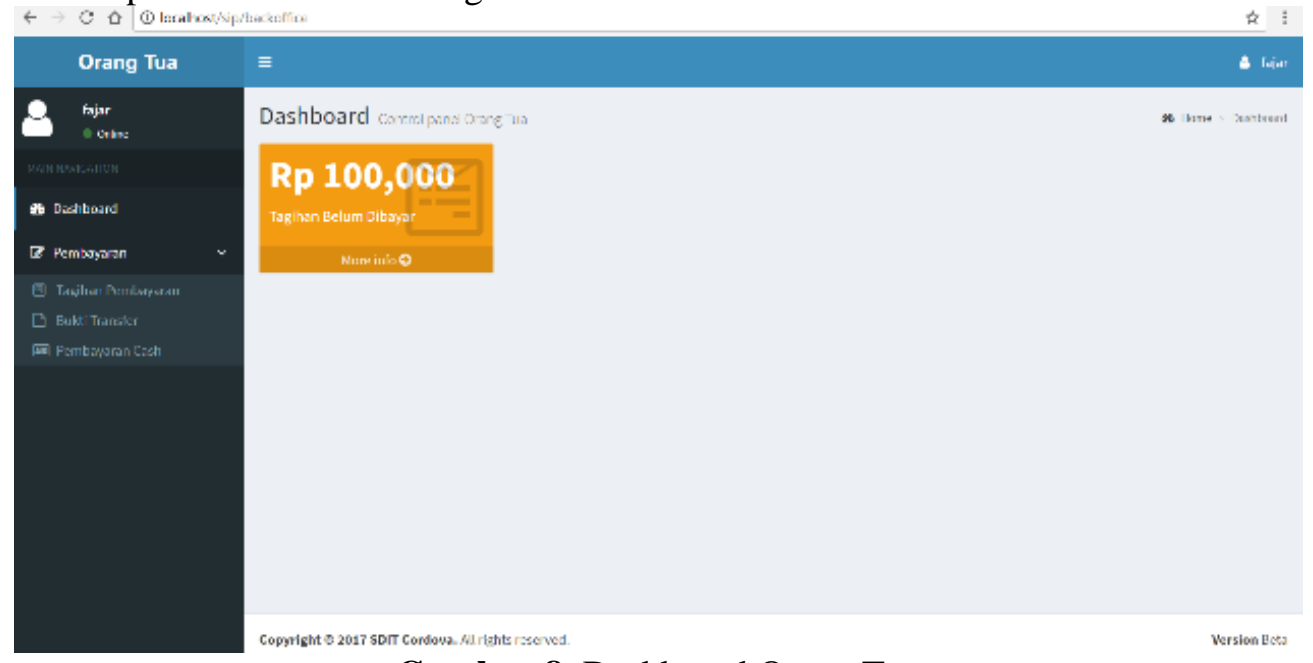

Gambar 8. Dashboard Orang Tua

Gambar 8 merupakan dashboard orang tua siswa yang digunakan untuk mengetahui informasi tagihan, upload bukti bayar dan pembayaran cash. 
6. Tampilan Tagihan Siswa

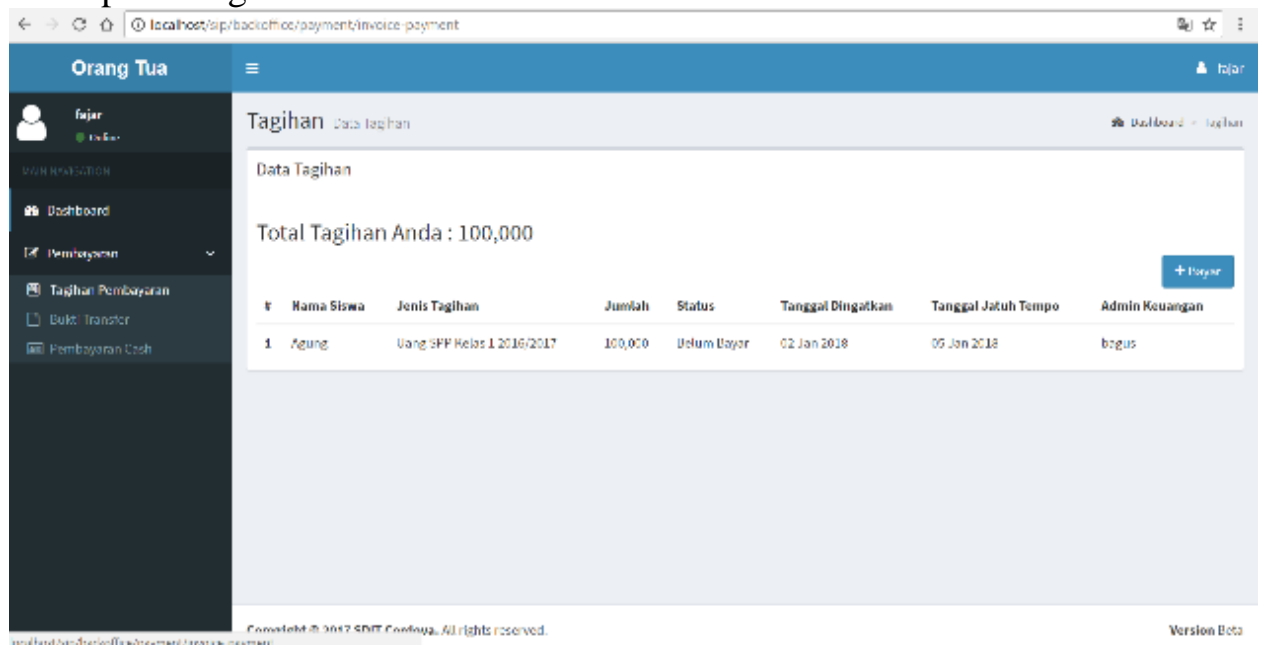

Gambar 9. Tampilan Tagihan Siswa

Pada gambar 9, orang tua siswa dapat melihat jumlah tagihan yang harus dibayarkan, halaman ini menampilkan nama siswa, jenis tagihan, jumlah, status, dan tanggal jatuh tempo. Pembayaran tagihan dapat dilakukan dengan cara transfer dan mengupload bukti bayar melalui sistem ini.

\section{KESIMPULAN}

Bagian ini memberikan simpulan yang singkat tentang penelitian yang dibahas pada artikel ini disertai dengan saran untuk pengembangan atau lanjutan penelitian berikutnya. Sistem informasi pembayaran sekolah berbasis web di SDIT Cordova 1 Kota Tangerang dapat menjadi solusi terbaik dalam proses transaksi yang terjadi pembayaran, karena dapat memberikan alternatif pembayaran melalui aplikasi online, dimana sebelumnya dilakukan dengan manual dengan cara membayar tunai (cash). Sistem Informasi Pembayaran yang dikembangkan ini dapat memberikan solusi untuk mengurangi terjadinya antrean di loket pembayaran, dengan adanya penyerahan bukti pembayaran melalui transfer yang dilakukan oleh masing-masing orang tua murid dimanapun berada. Serta memudahkan bagian keuangan untuk memantau daftar pembayaran siswa dan memudahkan dalam dalam pembuatan laporan keuangan.

\section{DAFTAR PUSTAKA}

[1] Arifin, M.Z., Huda, M.N. Pembuatan Dan Perancangan Sisitem Informasi Pembayaran Sekolah Dengan Microsoft Visual Fox Pro Di SMA Muhammadiyah 1 Jombang. Jurnal SAINTEKBU. 2012; Vol. 5 (2).

[2] Hasan, M.W. Pemanfaatan Teknologi SMS Gateway Pada Sistem Pembayaran SPP dan Tabungan Sekolah di SMA N 1 Nalumsari. Skripsi. Kudus: Universitas Muria Kudus. 2015.

[3] Adhani, M., dkk. Perancangan Sistem Informasi Penerimaan Siswa Baru dan Pembayaran SPP Menggunakan Zachman Framework. Prosiding Seminar Nasional Informatika. Medan. 2015; Vol. 1: 636-642. 